\title{
ARTIGOS
}

DOI 10.22478/ufpb.2317-6725.2019v24n41.45188

\section{Perguntas, respostas e pressupostos: uma proposta metodológica para o estudo do espaço}

\author{
Questions, answers and presuppositions: a methodological proposal for the study of \\ space
}

\section{Felipe Souza Leão de Oliveira}

https://orcid.org/0000-0003-1764-952X

Universidade Federal do Rio Grande do Sul

Resumo: O objetivo deste artigo é construir uma abordagem capaz de lidar com o problema do espaço em textos historiográficos, usando principalmente as obras dos historiadores Hayden White e Robin George Collingwood. Primeiro, articulamos o método de análise de pressuposições de White com a lógica de perguntas e respostas de Collingwood. Por fim, concluímos com uma demonstração prática de nossa abordagem, analisando os textos dos escritores brasileiros Luís da Câmara Cascudo e Gilberto Freyre a respeito de dois espaços: o "Brasil Holandês" e o "Nordeste".

Palavras-chave: Hayden White. Robin George Collingwood. Espaço.

Abstract: The objective of this article is to construct an approach capable of dealing with the problem of space in historiographical texts, using mostly the works of the historians Hayden White and Robin George Collingwood. First, we articulate White's method of presupposition analysis with Collingwood's logic of question and answer. In the end, we conclude with a practical demonstration of our approach, investigating the historiographical texts of two Brazilian writers, Luís da Câmara Cascudo and Gilberto Freyre, about two distinct spaces: the Brasil Holandês and the Nordeste.

Keywords: Hayden White. Robin George Collingwood. Space.

\section{Introdução}

O objetivo deste artigo é construir uma forma de problematizar o espaço em textos historiográficos, partindo das obras do norte-americano Hayden White e do inglês Robin George Collingwood. Isso significa que articularemos o método de análise de White e a lógica de perguntas e respostas de Robin George Collingwood com os conceitos de "lugar" e "espaço" de Michel de Certeau. Em seguida, realizaremos uma demonstração prática de nossa proposta, comparando os textos do escritor potiguar Luís da Câmara Cascudo (1898-1986) com aqueles do escritor pernambucano Gilberto Freyre (1900-1987) a respeito de dois espaços históricos: o Brasil Holandês e o Nordeste. Escolhemos as obras desses dois autores porque já trabalhamos com elas em nossa dissertação de mestrado. Assim, o presente artigo expande e aprofunda reflexões desenvolvidas anteriormente. 


\section{A historiografia do espaço}

Diversas formas de abordar o problema do espaço já foram trabalhadas por outros autores no passado. Eles problematizaram a categoria "espaço" e lidaram com recortes espaciais específicos de um ponto de vista histórico.

O geógrafo Douglas Santos, por exemplo, definiu a categoria "espaço" como uma construção histórica, cuja emergência histórica precisa ser investigada. Em seu estudo, Santos argumentou que ela foi construída a partir de contribuições como a linguagem matemática, a geometria analítica, o discurso geográfico, a mecânica newtoniana e a estética kantiana (SANTOS, 2002).

O historiador e cientista político Benedict Anderson, dialogando com a Antropologia e investigando o problema da nação, propôs que o espaço nacional fosse pensado como uma "comunidade política imaginada - e imaginada como sendo intrinsecamente limitada e, ao mesmo tempo, soberana" (Anderson, 2008, p. 32), de modo que seus habitantes "jamais conhecerão, encontrarão, ou sequer ouvirão falar da maioria de seus companheiros, embora todos tenham em mente a imagem viva da comunhão entre eles" (ANDERSON, 2008, p. 32).

De modo semelhante, o historiador Laurent Vidal pensou o espaço como um produto de forças históricas, valores, temas e questões julgadas importantes por uma dada sociedade. Para isso, ele escolheu Brasília como objeto de estudo, sugerindo que esta cidade fosse problematizada a partir da seguinte questão: "de que maneira a memória, a identidade de uma nação ou de uma comunidade pretende espacializar-se, ou melhor, quem ou o que produz uma cidade para nela depositar uma memória?" (Vidal, 2009, p. 16).

Outro historiador, Durval Muniz de Albuquerque Júnior, argumentou que o espaço não é uma verdade a ser descoberta, ou uma essência a ser desvendada. Ao invés disso, devemos pensá-lo como um produto de práticas discursivas e nãodiscursivas, como imagens e filmes, capazes de inventá-lo e torná-lo visível, dando-lhes uma identidade histórica própria. A partir desses pressupostos, Albuquerque Júnior estuda a invenção de um espaço específico: o Nordeste (ALBUQUERQUE JÚNIOR, 2009).

Em outra obra, o historiador inglês Keith Thomas investigou as atitudes dos seres humanos perante animais, plantas e paisagens que compõem o espaço que chamamos de "Natureza", ou "mundo natural". Para isso, Thomas escolhe a Inglaterra e o período que vai de 1500 a 1800, aproximadamente. O espaço inglês "natural", aqui, é visto como um produto de atitudes humanas, que sofrem ajustes e transformações em diferentes discussões e contextos, como aquele que diz respeito ao problema da exploração da Natureza em benefício da Humanidade (THOMAS, 2010).

A Natureza também é objeto de estudo do historiador inglês Simon Schama, para quem o espaço é "cultura antes de ser natureza; um constructo da imaginação projetado sobre mata, água, rocha" (SCHAMA, 1996, p. 70). Trabalhando com diferentes épocas e sociedades, e explorando uma grande quantidade de fontes (como a Literatura e registros e documentos oficiais), Schama propõe que os principais elementos usados na construção de um espaço são categorias, mitos e metáforas, ao invés de rios, rochas e plantas (SCHAMA, 1996).

De modo semelhante, o historiador Marc Bloch examinou as relações entre seres humanos e espaços ditos "naturais", concentrando sua análise em áreas rurais. Por exemplo: Bloch notou que regimes de servidão coletiva não duram muito em espaços 
abertos e irregulares, isto é, desprovidos de limites e regularidades bem estabelecidos. Além disso, observou que em espaços cercados e regulares os indivíduos tendem a mostrar atitudes mais individualistas, independentes e autossuficientes. A repartição e distribuição de espaços ditos "naturais", portanto, influenciam atitudes individuais e organizações sociais. O que Bloch propõe, entretanto, não é que o espaço seja apenas encarado como um produto de forças históricas, mas sim como sendo, ele mesmo, uma dessas forças, dotada de características próprias e capaz de moldar relações sociais e atitudes individuais diante do mundo (Bloch, 2001).

Em outro contexto, o arquiteto George Dantas investigou os elementos e matrizes do pensamento que informaram e influenciaram a construção da cidade colonial na historiografia brasileira (DANTAS, 2009, p. 29). Dantas propôs que o espaço fosse pensado como uma construção cultural, isto é, como um objeto simbólico moldado por embates sociais, bem como um produto de "relações recíprocas entre imaginação (dimensão da reflexão político-técnica) e imaginário (reflexão cultural) urbanos" (DANTAS, 2009, p. 57). O historiador Raimundo Arrais, de modo parecido, propôs que o espaço fosse abordado como um objeto simbólico formado por lutas, disputas, memórias e esquecimentos. A partir dessa proposta, Arrais investigou a formação de espaços públicos na cidade de Recife no período do Brasil imperial (Arrais, 2004). Uma abordagem similar foi adotada pela historiadora Raquel Glezer em um conjunto de ensaios sobre a cidade de São Paulo. Para ela, o espaço não pode ser tratado "como elemento isolado, mas [sim como algo] historicamente localizado" (GLEZER, 2007, p. 32). Dessa forma, até uma região geográfica é construção simbólica, ou seja, um "objeto criado" (GLEZER, 2007, p. 148).

Além de influenciar relações sociais e atitudes individuais, espaços também disciplinam corpos humanos. Esta abordagem, escolhida pelo historiador e filósofo Michel Foucault, é utilizada para o estudo de espaços de quartéis e prisões europeias nos séculos XVIII e XIX. Tais espaços foram escolhidos por Foucault pelo fato de moldarem e controlarem corpos humanos de forma explícita, e por vezes extrema, impondo comportamentos e formas de pensar e agir. Tais imposições, por sua vez, perpetuam e reproduzem relações de poder, o que traz sérias consequências para as relações mais íntimas e cotidianas entre os seres humanos (FOUCAULT, 2007).

Por fim, nosso último exemplo é aquele do crítico literário e cultural Stephen Greenblatt, autor da abordagem conhecida como "Novo Historicismo". Nela, anedotas supostamente banais e triviais são investigadas como formas únicas de olhar a realidade. Por exemplo: nos primeiros contatos entre europeus e nativos de terras americanas, Greenblatt problematiza o espaço a partir de relatos anedóticos de exploradores europeus. Neles, o "Novo Mundo" é descrito como um espaço "maravilhoso", um conceito que ao mesmo tempo descreve, significa e legitima sua posse. A escrita de anedotas, portanto, é um ato político, carregado de intenções e significados próprios (GREENBLATT, 1996).

Ao contrário dos autores citados até aqui, Hayden White não construiu reflexões explícitas sobre a categoria espaço. Collingwood também não. E, no entanto, a despeito disso, argumentaremos que seus escritos podem sim serem úteis para problematizarmos o espaço em textos historiográficos. 


\section{A abordagem}

Muitos trabalhos se limitam a ver a obra de Hayden White e Robin George Collingwood como contribuições à Teoria e Filosofia da História ${ }^{1}$. Essa leitura é compreensível, considerando os objetivos de seus textos; mas insuficiente, levando em conta as suas possibilidades. Explorar uma dessas possibilidades é o nosso objetivo. Para isso, adotaremos uma estratégia semelhante àquela usada pela historiadora Verónica Tozzi: construiremos uma abordagem onde uns métodos e conceitos são articulados e depois trazidos para a aplicação prática, tentando abrir assim possibilidades futuras de pesquisa (Tozzi, 2009).

Antes de voltarmos nossa atenção para os textos de White e Collingwood, precisamos esclarecer dois conceitos importantes para a nossa abordagem aqui: "lugar" e "espaço". Seguindo a proposta de Michel de Certeau, entendemos por "lugar" um conjunto de posições, dados e coordenadas - como os traços num mapa ou um desenho arquitetônico em uma folha de papel. O "espaço", por sua vez, é um "lugar praticado": um conjunto de posições, dados e coordenadas que recebem significados através de ações e atitudes, como o ato de caminhar ou escrever. Um exemplo de "espaço" é a rua que ganha um sentido para os que nela moram e outro para os que sobre ela escrevem. Outro exemplo é aquele de teatros e monumentos, interpretados de formas distintas por seus visitantes, apreciadores ou aqueles que escrevem sobre eles (CERTEAU, 2008, p. 201-202).

A partir desses conceitos seguiremos a sugestão de Robin George Collingwood, para quem o verbo "problematizar" significa investigar um dado objeto de estudo a partir de um método de pergunta e resposta. Podemos ver isso quando, em sua autobiografia, Collingwood escreve a respeito do Albert Hall Memorial, um espaço de memória do século XIX situado em Londres, encomendado pela Rainha Vitória ao arquiteto Sir George Gilbert Scott (1811-1872). Em seu texto, Collingwood defende que uma análise das intenções de Scott ou de seu contexto histórico não é suficiente: precisamos, além disso, reconstruir a pergunta que o arquiteto inglês estava tentando responder enquanto projetava tal espaço (COLLINGWOOD, 1939, p. 29-30 e 74). É nisso que consiste o seu "método de pergunta e resposta" ou "atividade questionadora". Agora, a partir dessas considerações, podemos definir o verbo "problematizar" como sendo um ato interpretativo que vê o espaço (um "lugar praticado") como uma resposta a uma pergunta formulada implícita ou explicitamente em um dado contexto histórico.

Mas se espaços são produtos de práticas como a escrita, que possuem uma lógica e pressupostos próprios, então a descrição e interpretação de um recorte espacial pode se beneficiar da análise desta lógica e destes pressupostos. Mas como fazermos isso? Uma possibilidade é encararmos o espaço do mesmo modo que Clifford Geertz abordou o problema da cultura: tratando-a como um texto (GEERTZ, 1973, p. 452). Isso permitiu que ele trouxesse ferramentas da filosofia para pensar seu objeto de estudo (GEERTZ, 1973, p. 6 e seguintes). Do mesmo modo, partindo da mesma premissa, podemos trazer ferramentas da análise textual para lidar com o problema do espaço. Para isto o livro Metahistory, de Hayden White, pode ser muito útil (WHITE, 1973).

Nessa obra, White procurou investigar o problema da imaginação histórica em textos historiográficos do século XIX, utilizando conceitos da Crítica Literária e da Linguística. Para isso, concentra sua análise nos pressupostos a respeito da história

\footnotetext{
${ }^{1}$ Por exemplo: Doran, 2013, Ankersmit; Domanska; Kellner, 2009 e Van Der Dussen, 1994.
} 
assumidos por autores como Alexis de Tocqueville e Jules Michelet. Para identificar e analisar esses pressupostos, White recorre a três conceitos: enredo, argumento formal e implicações ideológicas².

A noção de "enredo", no texto de White, significa pelo menos duas coisas: (1) o modo através do qual um determinado historiador concebe o processo histórico como um todo e (2) a estrutura de um processo histórico específico, que organiza e determina a narrativa adotada por um texto historiográfico. Este conceito de enredo por ser muito útil para pensarmos o problema do espaço. Vejamos o caso do historiador Leopoldo Von Ranke, estudado por White. Para o historiador alemão, o espaço nacional é uma expressão das virtudes e poderes de seu povo, de modo que qualquer narrativa ou reflexão histórica que decida ignorar o espaço da nação estaria reduzida a mero "humanitarismo sentimental" (WHITE, 1973, p. 175). Aqui estaria pressuposto um enredo onde a história humana, a despeito de quaisquer conflitos, é marcada pelo progresso, sendo capaz de produzir ordens sociais e políticas cada vez melhores e mais pacíficas ao longo do tempo. Este enredo, por sua vez, permite que o historiador alemão trate os espaços da nação e da Igreja como produtos naturais e inevitáveis, ao invés de meros resultados de forças históricas específicas. A consequência disso é a espacialização da própria História, ou seja, a redução de todo o processo histórico a um conjunto estático de relações entre entidades que geram formas mais desenvolvidas e complexas ao longo do tempo (WHITE, 1973, p. 177).

O conceito de "argumento formal", por sua vez, se refere à compreensão que um autor tem das relações entre fenômenos e entidades históricas no processo histórico como um todo ou em momentos históricos específicos. Voltando a Ranke, descobrimos que espaços e eventos são compreendidos como partes de processos mais amplos, que se agregam para formar um todo qualitativamente diferente dos componentes que o constituem (WHITE, 1973, p. 15). Assim, recortes espaciais como o espaço da nação devem ser analisados como partes de um processo histórico mais amplo, dotado de uma lógica própria: a lógica do progresso. Além disso, sendo ele mesmo um produto deste processo, o espaço da nação é interpretado como uma entidade cuja perfeição e complexidade decorrem da natural e inevitável marcha dos acontecimentos históricos.

Por fim, temos o conceito de "implicações ideológicas", que se refere às consequências éticas e políticas das pressuposições assumidas por um dado autor. Ainda no caso de Ranke, seus pressupostos foram adotados a partir de suas convicções sobre o que seria melhor e mais saudável para a civilização europeia (PAUL, 2004, p. 7). Uma das implicações disso é uma postura conservadora, onde o espaço nacional se transforma na culminação lógica, natural e mais desejável do desenvolvimento histórico europeu (WHITE, 1973, p. 173).

Assim, tanto os conceitos de White quanto os conceitos de Certeau e Collingwood, se unem para formar uma abordagem em que o espaço é investigado como um problema e analisado através dos pressupostos que o constroem. A seguir, faremos uma demonstração prática dos conceitos explicados até aqui. Para isso, analisaremos o diálogo entre o potiguar Luís da Câmara Cascudo e o pernambucano Gilberto Freyre sobre dois espaços históricos: o Brasil Holandês e o Nordeste.

\footnotetext{
2 Originalmente, White não usa o termo "pressuposição", mas sim "pressuposição metahistórica". Para os nossos propósitos aqui, o termo "pressuposição" (ou seu equivalente, "pressuposto") será suficiente. Em nossa leitura de White, seguimos a interpretação que o historiador Herman Paul (2004) fez dele, particularmente quando definimos termos como "pressuposição", "enredo", "argumento formal" e "implicações ideológicas".
} 


\section{A pergunta}

No livro Geografia do Brasil Holandês, publicado em 1956, o folclorista e historiador potiguar Luís da Câmara Cascudo estudou a cultura, economia e política do espaço ocupado pelos holandeses no Brasil entre 1630 e $1654^{3}$. O interesse de Cascudo por este recorte espacial remonta à década de 1920 (Cascudo, 1940b; Instituto Arqueológico, 1925), mas ele só transforma o entusiasmo em livro décadas depois, quando já estava plenamente familiarizado com as fontes relativas ao domínio holandês.

No total, Cascudo divide seu livro em duas partes: "Presença Holandesa no Nordeste do Brasil" e "Geografia do Brasil Holandês". A primeira foi separada em 22 seções, numeradas com algarismos romanos. Em cada uma delas Cascudo explora um aspecto do Brasil Holandês, como questões raciais, comerciais e políticas. A segunda parte é dividida em 8 seções, dedicadas às porções distintas do território ocupado pelos holandeses: Bahia, Sergipe, Alagoas, Pernambuco, Paraíba, Rio Grande do Norte, Ceará e Maranhão.

Para problematizarmos o espaço aqui, seguindo nossa abordagem, iniciaremos com o método de Collingwood: qual a pergunta que Cascudo tenta responder quando descreve e analisa o espaço do Brasil Holandês? Para reconstruirmos essa pergunta e descobrirmos sua resposta, devemos ter em mente que o Geografia do Brasil Holandês foi publicado como um volume da coleção "Documentos Brasileiros", criada em 1936 pelo então influente editor brasileiro José Olympio, dono da editora Livraria José Olympio. Nesta época, coleções como a "Brasiliana" (da Companhia Editora Nacional) e "Problemas Políticos Contemporâneos" (também da José Olympio) surgiam num momento em que intelectuais e eruditos brasileiros refletiam sobre a identidade nacional (FRANZINI, 2007). No caso da "Documentos Brasileiros", seu primeiro editor foi Gilberto Freyre, alguém que trouxe o espaço do Nordeste para uma posição central, colocandoo "entre as categorias cognitivas da brasilidade, palavra de valor central entre aquelas que passariam a controlar a recepção e a hierarquia dos discursos nacionais legítimos" (SORÁ, 2010, p. 193).

Estando de acordo com a lógica da coleção e das ideias de Freyre, o livro Geografia do Brasil Holandês constrói uma descrição e análise da "Presença Holandesa no Nordeste do Brasil" (grifo nosso). Isso dá ao território sob domínio holandês uma forma peculiar, muito parecido com a disposição do Nordeste em pleno século XX - algo semelhante ao que o próprio Freyre havia feito (FREYRE, 2004). Lembremos, porém, que

Até meados da década de 1910, o Nordeste não existia. Ninguém pensava em Nordeste, os nordestinos não eram percebidos, nem criticados como uma gente de baixa estatura, diferente e mal adaptada. Aliás, não existiam. (RAGO, 2009, p. 13)

A palavra "Nordeste" foi usada pela primeira vez no fim da década de 1910 para se referir à área de atuação de um órgão federal conhecido como Inspetoria Federal de Obras Contra as Secas (IFOCS). Nesta ocasião, o espaço nordestino surgiu como um território único, marcado por fenômenos que o distingue dos demais, como seca, movimentos messiânicos e cangaço (ALBUQUERQUE JÚNIOR, 2009, p. 81 e seguintes).

\footnotetext{
${ }^{3}$ O livro Geografia do Brasil Holandês foi brevemente analisado por Pedro Puntoni (2012) e citado, mesmo que apenas de passagem, por Francisco Isaac Dantas de Oliveira (2014). Ele ainda aguarda estudos mais aprofundados.
} 
Antes do Brasil Holandês, o território português na América havia sido retalhado em nove Capitanias Hereditárias: Pernambuco, Porto Seguro, Bahia de Todos os Santos, Espírito Santo, Itamaracá, São Vicente, Maranhão, Ilhéus e Ceará (VAINFAS, 2000, p. 82 e 93). Mais tarde, no período do Brasil Holandês, uma nova divisão é criada, separando Capitanias Hereditárias (São Vicente, Santo Amaro, Espírito Santo, Porto Seguro, Ilhéus, Pernambuco e Itamaracá) de Capitanias da Coroa (Rio de Janeiro, Bahia, Sergipe, Paraíba, Rio Grande, Ceará, Maranhão e Pará) (VAINFAS, 2000, p. 9394). Contudo, essas divisões históricas tinham pouca importância para Cascudo e Freyre, que buscavam entender a identidade nordestina como se ela e seus limites geográficos sempre tivessem existido. Cascudo, por exemplo, escreveu que

[...] o Holandês não é pra mim um assunto mas uma Presença. Conquistou e dirigiu a região brasileira em que nasci e vivo, a mais amada e conhecida. Não encontro apenas nos livros, mapas, nótulas, e relatórios da Geoctroyerd Westindische Companie [Companhia das Índias Ocidentais], mas na recordação inconsciente de sua visita de vinte e quatro anos, inapagável na memória nordestina. [grifos nossos] (CASCUDO, 1956, p. 13)

A partir daí, um estudo do Brasil Holandês deve lidar com um problema central: o "drama de uma colonização batava no nordeste [sic] brasileiro" (Cascudo, 1956, p. $66)$.

Gilberto Freyre, por sua vez, via na influência holandesa uma oportunidade de distinguir o Nordeste do resto do país, dando-lhes uma identidade própria (Albuquerque Júnior, 2009, p. 89). Em um texto de 25 de setembro de 1941, publicado na revista "O Cruzeiro", o autor pernambucano defendeu que o domínio holandês não foi melhor que a colonização lusitana. Apesar disso, tal domínio "enriqueceu o Brasil - principalmente Pernambuco - de uma variedade de cultura e de sangue que são parte da nossa história e da nossa vida. Estão em nós. Incorporaram-se ao todo brasileiro" (Freyre, 1941, p. 1819). Por este motivo, torna-se fundamental que pesquisadores dediquem-se cada vez mais ao

estudo paciente daqueles contatos, daquelas contribuições de sangue e de cultura, de esclarecimento dos processos através dos quais se processaram aquelas relações e a incorporação dos elementos chamados flamengos ao tipo étnico, à fisionomia moral e à paisagem de largo trecho brasileiro. (FREYRE, 1941, p. 18-19)

Um desses pesquisadores foi Cascudo, alguém que Freyre conhecia desde a década de 1920, quando o pernambucano introduziu o potiguar ao meio artístico e intelectual de Recife (SALES NETO, 2008, p. 117 e seguintes). Em maio de 1924, os dois participam da criação do Centro Regionalista do Nordeste, uma instituição sediada na capital pernambucana com o objetivo de "desenvolver o sentimento de unidade do Nordeste, que é tão claramente caracterizada na sua condição geográfica e evolução histórica" (Centro Regionalista do Nordeste, 1924). Em Natal, o jornal "A Imprensa" cujo dono era o pai de Cascudo - mostrou seu apoio a essa instituição (Centro Regionalista, 1924). Assim, em busca do "sentimento de unidade do Nordeste", Freyre e Cascudo formulam a seguinte pergunta: qual é a identidade deste espaço?

\section{A resposta}

Uma possível resposta era o próprio Brasil Holandês. Cascudo deixa isso muito claro quando diz que o principal problema no estudo deste espaço é o "drama de uma 
colonização batava no nordeste brasileiro" (CASCUDO, 1956, p. 66; grifo nosso). Assim, em uma única frase, espaços distintos, situados em momentos diferentes ("colonização batava" e "nordeste brasileiro") são articulados em um mesmo processo histórico. $\mathrm{Na}$ maioria das vezes, dramas giram em torno de conflitos (BALDICK, 2008, p. 97; FRYE, 1957, p. 282 e seguintes), de modo que o conflito central no "Brasil Holandês" ocorre entre duas "raças": a holandesa e a portuguesa. As demais, como negros e indígenas, são meros coadjuvantes. Os "negros" são descritos como personagens indiferentes às lutas entre europeus, preocupados apenas com a fuga de sua própria exploração e/ou cativeiro (Cascudo, 1956, p. 58-61). "Indígenas", enquanto isso, são mais participativos - especialmente quando lutam do lado holandês contra o português (Cascudo, 1956, p. 61-67).

A escolha de "raças" como personagens centrais e secundários é compreensível quando nos lembramos que Cascudo escreveu seu livro na década de 1940, um período em que ciências preocupadas com questões raciais exerciam grande influência sobre eruditos e intelectuais brasileiros (Schwarcz, 1993). Dentre elas, uma em particular foi bastante influente na obra do escritor potiguar: a Antropogeografia (Cascudo, 1940c). Fundada no século XIX por um pensador alemão chamado Friedrich Ratzel (18441904), seu principal objetivo era estudar a "influência que as condições naturais exercem sobre a humanidade" (MORAES, 2007, p. 69). Assim, por exemplo, um adepto desta ciência deve se voltar para o problema do contato entre um ou mais povos, analisando a interação entre raças distintas (Moraes, 2007, p. 69-70). Nessa primeira metade do século XX, a Antropogeografia fazia muito sucesso no Brasil. Em 1941, por exemplo, o governo brasileiro chega a criar uma "Comissão Técnica Permanente de Antropogeografia Brasileira", da qual o próprio Cascudo fez parte (Conselho Nacional de Geografia, 1941). Um ano depois, ele registra as "melhores recordações" de sua participação, elogiando o ponto de vista "antropogeográfico" como sendo capaz de articular "fatos humanos" e "expressões geográficas" (CASCUDO, 1942).

A partir daí, no Geografia do Brasil Holandês, vários desses "fatos humanos" serão descritos e analisados: conflitos (CASCUDO, 1956, p. 107-293), alimentação (CASCUDO, 1956, p. 37-39), arquitetura (CASCUDO, 1956, p. 45-58), vocabulário (CASCUDO, 1956, p. 72-75) e instituições políticas (Cascudo, 1956, p. 92-96). Destes, porém, Cascudo enfatiza a guerra biológica entre diferentes raças (CASCUDO, 1956, p. 20-28 e p. 35-37). Por exemplo: uma vitória militar holandesa é registrada como algo frágil e momentâneo (CASCUDO, 1956, p. 14-20), ao contrário da supostamente sólida e duradoura supremacia racial do português, decorrente de sua capacidade de adaptação aos trópicos (CASCUDO, 1956, p. 89-92). Estes últimos, portanto, aparecem como seres formados por uma constituição biológica flexível e mutável (CASCUDO, 1956, p. 73), enquanto os holandeses seriam dotados de uma estrutura inflexível, além de preocupados somente com riquezas materiais (CASCUDO, 1956, p. 44-45) - uma preocupação que, diga-se de passagem, Cascudo julga ser igualmente inútil e efêmera, um verdadeiro "programa repugnante de utilitarismo econômico" (Cascudo, 1956, p. 78).

Essa lógica racial, entretanto, também foi útil para Freyre em seu livro Casa Grande e Senzala, onde o problema da miscigenação surge como questão central (FREYRE, 2006, p. 31). Ao contrário de Cascudo, porém, Freyre adota um tom conciliador, argumentando que a "ocupação holandesa" deixará

na face de um Brasil ainda socialmente adolescente cicatrizes honrosas: quase do mesmo gênero daquelas de que se gabavam outrora os estudantes alemães. 
Cicatrizes de combate. Sinais de resistência. Marcas de luta. (FREYRE, 2008, p. 15)

A partir daí surge uma "'consciência de espécie' - no caso, a luso-brasileira hoje afirmada em consciência nacional. O invasor despertou-a". No Brasil Holandês seria possível ver "um contato entre grupos e culturas antagônicas que tiveram, entretanto, suas zonas de confraternização ou, pelos menos, de interpenetração, marcando-se uns aos outros com sinais até de sangue" (FREYRE, 2008, p. 15). Desse modo,

sobre os antagonismos, predominaram as forças de contemporização e de reciprocidade cultural, desenvolvendo-se, para os vários elementos, um ambiente de liberdade criadora, que talvez não exista tão ampla em nenhum outro país de gente mestiça. (FREYRE, [19--])

Assim, enquanto Cascudo atribui um papel secundário a negros e indígenas, Freyre confere-lhes um papel central, fazendo-os interagir através da mestiçagem. $O$ resultado disso é a suposta manutenção dos traços holandeses em pleno século XX, como

a sobrevivência de olhos azuis e de sangue flamengo em nosso país, embora certos casos, já tão diluído noutros sangues que há até mulatos quase negros, e não apenas sararás esbranquiçados, entre os descendentes [...]. (FREYRE, 2008, p. 1516)

Dessa forma, "As marcas que a ocupação holandesa do Norte deixou no Brasil são das que dificilmente desaparecem não só do corpo como da consciência - e do inconsciente - de um povo" (FREYRE, 2008, p. 16). Cascudo, todavia, não concorda: a ideia do holandês como sendo "responsável pelos cabelos loiros e olhos azuis, ainda visíveis no Nordeste", para ele, é uma ilusão. Essas feições europeias, segundo seu argumento, seriam na verdade herança dos portugueses, um povo de "estatura avantajada", cuja cor branca seria preservada e reproduzida ao longo do tempo por meio de um processo de "arianização" - não de miscigenação (CASCUDO, 1940a). Ao fim deste processo, sobreviveriam apenas os traços daqueles portugueses dotados de "fausto e posses", capazes de criar no Brasil uma "aristocracia ruralenga [sic]" (CASCUDO, 1940a) Mas isso não é tudo:

Nós, do Nordeste, especialmente os que conhecem de perto o velho sertão, sabemos da existência teimosa, da sobrevivência admirável, dos tipos loiros, em grandes áreas, fixando-se mesmo em famílias inteiras [...]. [grifo do autor] (CASCUDO, 1940a)

Tal "sobrevivência admirável", contudo, é uma exclusividade portuguesa: "Nunca a dominação holandesa se infiltrou a ponto de ser determinante". Os holandeses viviam em guarnições e fortalezas, saindo apenas para o "estupro nas [sic] cunhãs". As brasileiras até chegavam a se casar com eles, mas "ficavam conhecidas e marcadas na reprovação católica e legalista”. No geral, idioma, raça, costume e religião são fatores que afastam brasileiros e holandeses, criando "uma distância inda [sic] maior que o ódio entre opressor e oprimido". Conclusão: "Não creio na influência antropológica do holandês no nordeste brasileiro"; e em "nenhum sinal antropológico [que] se fixaria através do melting-pot indígena-negro, onde se operaria a concedida mestiçagem [grifo do autor]" (CASCUDO, 1940a). E mais: "Etnicamente não me parece provável que se 
possa afirmar olhos azuis, cabelo claro e pele branca como índices da ascendência holandesa" (CASCUDO, 1956, p. 92).

\section{O enredo}

Mas como essas interpretações sobre o Brasil Holandês respondem à questão da identidade nordestina? Um exame da estrutura do enredo assumida por ambos pode ser revelador. Adaptando o conceito de White para os nossos propósitos aqui, entendemos por "enredo" a estrutura narrativa adotada implicitamente por um autor, utilizada para moldar e atribuir significados a um dado recorte espacial.

O enredo assumido por Cascudo gira em torno de um conflito entre portugueses e holandeses, cujo fim é a vitória biológica dos portugueses sobre o "invasor" holandês, enquanto este último tem seu legado apagado, reduzido a mera "recordação inconsciente" na imaginação popular. Seu enredo, desse modo, termina com o triunfo de uma "raça" (a portuguesa) sobre outra (a holandesa). E assim, o Brasil Holandês responde ao Nordeste mostrando o que ele poderia ter sido, mas, felizmente (para Cascudo) nunca chegou a ser.

Para Freyre, ao contrário, o Brasil Holandês não é apenas um espaço de conflitos e possibilidades: é a própria evidência histórica dos elementos que constituem a identidade nordestina no presente. Adotando um tom conciliador, Freyre pressupõe um enredo onde conflitos no Brasil Holandês se tornam motivo de orgulho, "cicatrizes honrosas", "sinais de resistência" e "marcas de luta". Desses conflitos não saem vencedores e perdedores. E tais embates, apesar importantes, são temporários: se por um lado deixam traços, por outro devem ser superados. O resultado geral é positivo, e por meio dessa narrativa as diferentes raças dão origem a um Nordeste miscigenado e harmonioso. No enredo freyriano, o "drama" do Brasil Holandês responde ao Nordeste mostrando os elementos que oriundos do passado, dão forma à identidade dessa região em pleno século $X X$.

\section{$\mathrm{O}$ argumento formal}

Adaptando o conceito de White para os nossos propósitos aqui, entendemos por "argumento formal" a compreensão assumida por um autor a respeito dos tipos de relações entre os elementos históricos que compõem o recorte espacial por ele descrito e analisado.

Cascudo estuda os elementos que compõem o Brasil Holandês por meio de uma biologia da sobrevivência, onde tão somente aqueles mais bem adaptados são capazes de permanecer. Além disso, tanto os valores portugueses quanto o seu modo de vida aristocrático superam os valores burgueses e comerciais dos "invasores" holandeses. Por meio dessa compreensão, o Nordeste é reduzido a um espaço homogêneo, fruto de uma seleção de entidades (raças) e de suas características ao longo do tempo.

Freyre, por sua vez, compreende o espaço nordestino a partir da integração por meio da miscigenação. Tal integração, contudo, não aponta vencedores e perdedores. Ela não seleciona: se limita a apontar os conflitos que aconteceram e foram superados, destacando a conciliação e a mistura daí decorrentes. Assim, o Nordeste aparece como um espaço mais bem acabado por causa da coexistência de entidades históricas (como as raças) que o formam ao longo do tempo. Portanto, nem uma cópia idêntica e nem uma diferença radical: o espaço nordestino nada rejeita, sendo apenas uma síntese melhor e mais complexa. 


\section{As implicações ideológicas}

Adaptando White para os nossos propósitos aqui, entendemos por "implicações ideológicas" as consequências éticas e políticas do enredo e do argumento formal assumidos por um dado autor.

As implicações ideológicas dos textos de Freyre e Cascudo são semelhantes. Ambos são conservadores no que diz respeito ao ritmo das mudanças temporais. Em seus textos, o processo histórico se desenrola através de um padrão lento e gradual, o que nem conflitos são capazes de alterar. Isso significa, por exemplo, que batalhas e guerras são virtualmente ignoradas, em nome de um ritmo temporal determinado somente pela lógica racial e biológica.

Portanto, a despeito das diferenças entre enredos e argumentos formais, as implicações ideológicas são essencialmente as mesmas. O leitor aprende que a relação entre uma resposta (o Brasil Holandês) e uma pergunta (o Nordeste) se dá através de uma relação temporal cujo valor central (e esta é uma escolha ética e política) é o progresso. A partir dele, um espaço mais primitivo e conflituoso sempre revela um outro mais avançado e melhor, cujos elementos constitutivos sempre estiveram presentes no espaço anterior - mesmo que muitos sejam descartados, segundo uma lógica de sobrevivência, ou igualmente mantidos, de acordo com o princípio da miscigenação.

\section{Conclusão}

Neste artigo, defendemos uma forma de problematizar o espaço a partir dos escritos de Hayden White, os conceitos de "lugar" e "espaço" de Michel de Certeau e uma ideia de "problema" construída a partir das reflexões de Robin George Collingwood. Em seguida, demonstramos a utilidade prática dessa abordagem analisando o diálogo entre Luís da Câmara Cascudo e Gilberto Freyre a respeito do espaço do Brasil Holandês e do Nordeste. Concluímos que um espaço oferece um tipo de resposta a identidade do outro, e que, a despeito das diferenças, suas implicações ideológicas são essencialmente as mesmas. Esperamos que nosso estudo seja um primeiro passo no diálogo entre os textos de Hayden White e Robin Collingwood com a atual discussão a respeito da relação entre História e Espaço

Por fim, uma observação: o leitor familiarizado com a obra de White vai notar que não incluímos em nossa proposta o conceito de "tropo", um termo importante em sua obra. A razão disto é simples: concordamos com Herman Paul (2004) quando este último escreve que White não estabeleceu uma diferença significativa entre "argumento formal" e "tropo", particularmente no Metahistory. Esses dois conceitos foram criados neste livro com o mesmo objetivo: analisar os modos de compreensão dos tipos de relações entre fenômenos e entidades históricas assumidos por um dado autor (Paul, 2004 , p. 8). Acreditamos que os tropos só vão ganhar um significado mais distinto e ambicioso em outro livro de White, o Tropics of Discourse. Neste último, ambos aparecem como instrumentos de análise de modos de consciência histórica, incluindo o poder que esses modos tem de determinar a forma e conteúdo de textos historiográficos (White, 1978, p. 1 e seguintes). Seriam esses modos de consciência histórica úteis para o estudo da relação entre História e Espaço? Somente pesquisas futuras dirão. 


\section{Referências}

ALBUQUERQUE JÚNIOR, Durval Muniz de. A invenção do Nordeste e outras artes. 4 ed. rev. São Paulo: Cortez, 2009.

ANDERSON, Benedict. Comunidades Imaginadas. São Paulo: Companhia das Letras, 2008.

ANKERSMIT, Frank; DOMANSKA, Ewa; KELLNER, Hans (ed.). Re-Figuring Hayden White. Stanford: Stanford University Press, 2009.

BALDICK, Chris. Oxford Dictionary of Literary Terms. 3. ed. Oxford: Oxford University Press, 2008.

BLOCH, Marc. A Terra e seus Homens: agricultura e vida rural nos séculos XVII e XVIII. Bauru: EDUSC, 2001.

CASCUDO, Luís da Câmara. Acta Diurna. A República, Natal, 27 jan. 1940a.

CASCUDO, Luís da Câmara. Acta Diurna. A República, Natal, 05 mar. 1940b.

CASCUDO, Luís da Câmara. Acta Diurna. A República, Natal, 14 set. 1940c.

CASCUDO, Luís da Câmara. Acta Diurna. A República, Natal, 21 maio 1942.

CASCUDO, Luís da Câmara. Geografia do Brasil Holandês. Rio de Janeiro: José Olympio, 1956.

CENTRO Regionalista. Jornal do Commercio, Recife, 25 maio 1924.

CENTRO Regionalista do Nordeste. Diário de Pernambuco, Recife, 11 maio 1924.

CERTEAU, Michel de. A invenção do cotidiano: artes de fazer. 14. ed. Petrópolis, RJ: Vozes, 2008.

COLLINGWOOD, R. G. An Autobiography. Oxford: Oxford University Press, 1939.

CONSELHO NACIONAL DE GEOGRAFIA. A República, Natal, 10 ago. 1941.

DANTAS, George Alexandre Ferreira. A formação das representações sobre a cidade colonial no Brasil. 2009. Tese (Doutorado em Teoria e História da Arquitetura e do Urbanismo) - Escola de Engenharia de São Carlos, Universidade de São Paulo, São Carlos, 2009.

DORAN, Robert (ed.). Philosophy of History after Hayden White. London: Bloomsbury, 2013.

FOUCAULT, Michel. Vigiar e Punir: história da violência nas prisões. 33 ed. Petrópolis, Vozes, 2007.

FRANZINI, Fabio. À sombra das palmeiras: a Coleção Documentos Brasileiros e as transformações da historiografia nacional (1936-1959). 2006. Tese (Doutorado em História Social) - Faculdade de Filosofia, Letras e Ciências Humanas, Universidade de São Paulo, São Paulo, 2007. 
FREYRE, Gilberto. Prefácio. In: MELLO, José Antônio Gonsalves de. Tempo dos Flamengos: influência da ocupação holandesa na vida e na cultura do norte do Brasil. 5 ed. Rio de Janeiro: Topbooks; Univercidade, 2008, p. 15-23.

FREYRE, Gilberto. Nordeste. .7 ed. São Paulo: Global, 2004.

FREYRE, Gilberto. O domínio holandês no Brasil. O Cruzeiro. Rio de Janeiro, 23 set. 1941.

FREYRE, Gilberto. Casa Grande e Senzala: formação da família brasileira sob o regime da economia patriarcal. 51 ed. rev. São Paulo: Global, 2006.

FREYRE, Gilberto. Raça e Cultura. Folha de Minas. Belo Horizonte, [19--].

FRYE, Northrop. Anatomy of Criticism: four essays. Princeton: Princeton University Press, 1957.

GEERTZ, Clifford. The Interpretation of Cultures: selected essays. New York: Basic Books, 1973.

GLEZER, Raquel. Chão da terra e outros ensaios sobre São Paulo. São Paulo: Alameda, 2007.

GREENBLATT, Stephen. Possessões maravilhosas: o deslumbramento do Novo Mundo. São Paulo: Editora da Universidade de São Paulo, 1996.

INSTITUTO ARQUEOLÓGICO. Diário de Pernambuco, Recife, 27 nov. 1925.

MORAES, Antônio Carlos Robert. Geografia: pequena história crítica. 21 ed. São Paulo: Annablume, 2007.

OLIVEIRA, Francisco Isaac Dantas de. O fio da memória: as paisagens do Brasil Holandês. História Revista, Goiânia, v. 19, n. 2, 2014, p. 159-186.

PAUL, Herman. Metahistorical Prefigurations: Toward a Re-Interpretation of Tropology in Hayden White. Journal of Interdisciplinary Studies in History and Archaeology, v. 1, n. 2, 2004, p. 1-19.

PUNTONI, Pedro. No tempo dos flamengos: memória e imaginação. In: VIEIRA, Hugo C.; GALVÃO, Nara N. Pires; SILVA, Leonardo Dantas. (Orgs.). Brasil Holandês: história, memória e patrimônio compartilhado. São Paulo: Alameda, 2012, p. 31-46.

RAGO, Margareth. Prefácio: Sonhos de Brasil. In: ALBUQUERQUE JÚNIOR, Durval Muniz de. A invenção do nordeste e outras artes. 4 ed. rev. São Paulo: Cortez, 2009, p. 13-19.

SALES NETO, Francisco Firmino. Palavras que silenciam: Câmara Cascudo e o regionalismo-tradicionalista nordestino. João Pessoa: Editora Universitária/UFPB, 2008.

SANTOS, Douglas. A reinvenção do espaço: diálogos em torno da construção do significado de uma categoria. São Paulo: Editora UNESP, 2002.

SCHAMA, Simon. Paisagem e Memória. São Paulo: Companhia das Letras, 1996.

SCHWARCZ, Lilia Moritz. O espetáculo das raças: cientistas, instituições e questão racial no Brasil 1870-1930. São Paulo: Companhia das Letras, 1993. 
SORÁ, Gustavo. Brasilianas: José Olympio e a gênese do mercado editorial brasileiro. São Paulo: Edusp: Com-Arte, 2010.

TOZZI, Verónica. Figuring the Malvinas Experience: Heuristic and History as an unfulfilled promise. In: ANKERSMIT, Frank; DOMANSKA, Ewa; KELLNER, Hans (ed.). Re-Figuring Hayden White. Stanford: Stanford University Press, 2009, p. 261-281.

THOMAS, Keith. O homem e o mundo natural: mudanças de atitude em relação às plantas e aos animais (1500-1800). São Paulo: Companhia das Letras, 2010.

VAINFAS, Ronaldo (org.). Dicionário do Brasil Colonial. Rio de Janeiro: Objetiva, 2000.

VAN DER DUSSEN, Jan. Editor's introduction. In: COLLINGWOOD, R. G. The Idea of History. ed. rev. Oxford: Oxford University Press, 1994.

VIDAL, Laurent. De Nova Lisboa a Brasília: a invenção de uma capital (séculos XIX-XX). Brasília: Editora Universidade de Brasília, 2009.

WHITE, Hayden. Metahistory: the historical imagination in nineteenth-century Europe. Baltimore: Johns Hopkins University Press, 1973.

WHITE, Hayden. Tropics of discourse: essays in cultural criticism. Baltimore: The John Hopkins University Press, 1978.

\section{Notas de autoria}

Felipe Souza Leão de Oliveira é graduado em História pela Universidade Federal do Rio Grande do Norte. Mestre em História pela Universidade Federal do Rio Grande do Norte. Doutor em História pela Universidade Federal do Rio Grande do Sul. E-mail: felipesldoliveira@gmail.com.

\section{Como citar esse artigo de acordo com as normas da revista}

OLIVEIRA, Felipe Souza Leão de. Perguntas, respostas e pressupostos: uma proposta metodológica para o estudo do espaço. Sæculum - Revista de História, v. 24, n 41, p. 10-23, 2019.

\section{Contribuição de autoria}

Não se aplica.

\section{Consentimento de uso de imagem}

Não se aplica.

\section{Aprovação de comitê de ética em pesquisa}

Não se aplica.

\section{Licença de uso}

Este artigo está licenciado sob a Licença Creative Commons CC-BY. Com essa licença você pode compartilhar, adaptar, criar para qualquer fim, desde que atribua a autoria da obra.

\section{Histórico}

Recebido em 29/03/2019.

Aprovado em 13/11/2019. 